\title{
Body Temperature and Activity Rhythms Under Different Photoperiods in High Arctic Svalbard ptarmigan (Lagopus muta hyperborea)
}

\author{
Daniel Appenroth ${ }^{1 *}$, Andreas Nord ${ }^{1,2}$, David G. Hazlerigg ${ }^{1}$ and Gabriela C. Wagner ${ }^{1,3 *}$ \\ 'Arctic Chronobiology and Physiology, Arctic and Marine Biology, UiT The Arctic University of Norway, Tromsø, Norway, \\ ${ }^{2}$ Section for Evolutionary Ecology, Department of Biology, Lund University, Lund, Sweden, ${ }^{3}$ Division of Forest and Forest \\ Resources, Norwegian Institute of Bioeconomy Research (NIBIO), Tromsø, Norway
}

\section{OPEN ACCESS}

Edited by:

Charalambos P. Kyriacou,

University of Leicester,

United Kingdom

Reviewed by:

Cory Williams,

University of Alaska Fairbanks,

United States

Gisele Akemi Oda,

University of São Paulo, Brazil

${ }^{*}$ Correspondence:

Gabriela C. Wagner

gabriela.wagner@nibio.no; gwa011@uit.no

Daniel Appenroth

daniel.appenroth@uit.no

Specialty section:

This article was submitted to Chronobiology,

a section of the journal

Frontiers in Physiology

Received: 26 November 2020 Accepted: 15 February 2021

Published: 08 March 2021

Citation:

Appenroth D, Nord A, Hazlerigg DG and Wagner GC (2021) Body Temperature and Activity Rhythms Under Different Photoperiods in High Arctic Svalbard ptarmigan

(Lagopus muta hyperborea).

Front. Physiol. 12:633866.

doi: 10.3389/fphys.2021.633866
Organisms use circadian rhythms to anticipate and exploit daily environmental oscillations. While circadian rhythms are of clear importance for inhabitants of tropic and temperate latitudes, its role for permanent residents of the polar regions is less well understood. The high Arctic Svalbard ptarmigan shows behavioral rhythmicity in presence of light-dark cycles but is arrhythmic during the polar day and polar night. This has been suggested to be an adaptation to the unique light environment of the Arctic. In this study, we examined regulatory aspects of the circadian control system in the Svalbard ptarmigan by recording core body temperature $\left(T_{\mathrm{b}}\right)$ alongside locomotor activity in captive birds under different photoperiods. We show that $T_{\mathrm{b}}$ and activity are rhythmic with a 24-h period under short (SP; L:D 6:18) and long photoperiod (LP; L:D 16:8). Under constant light and constant darkness, rhythmicity in $T_{\mathrm{b}}$ attenuates and activity shows signs of ultradian rhythmicity. Birds under SP also showed a rise in $T_{\mathrm{b}}$ preceding the light-on signal and any rise in activity, which proves that the light-on signal can be anticipated, most likely by a circadian system.

Keywords: Arctic, chronobiology, circadian rhythm, heterothermy, photoperiod, thermoregulation, Svalbard ptarmigan

\section{INTRODUCTION}

The Earth's rotation around its own axis causes daily oscillations in environmental factors such as light and ambient temperature. Circadian rhythms have evolved to maintain behavioral, physiological, and metabolic synchrony with these ambient cycles, and to anticipate changing conditions within a day. Disruption of this synchrony can consequently affect fitness and survival (DeCoursey et al., 1997, 2000; DeCoursey and Krulas, 1998; Daan et al., 2011; Spoelstra et al., 2016). Biochemical oscillators, so-called circadian clocks, endogenously produce rhythmicity by transcription-translation-feedback loops, in which clock genes are expressed and subsequently inhibited due to the action of their own translated proteins (Hardin et al., 1990; Darlington et al., 1998). In higher vertebrates, circadian rhythmicity is ultimately produced by a single hypothalamic 
master clock (the suprachiasmatic nucleus in mammals) or a network of clocks (in the pineal gland, eyes and the hypothalamus of bird and reptiles; Menaker et al., 1997). These master clocks entrain to the environmental cycle primarily through the lightdark signal (Pittendrigh, 1960) and impose rhythmicity onto peripheral tissue, e.g., by circulating hormones such as melatonin produced in the pineal gland (Pevet and Challet, 2011). This ultimately leads to rhythmic physiology and behavior.

At tropical and temperate latitudes, the light-dark progression and other environmental factors, such as ambient temperature, cycle on a 24 -h period throughout the year. This is not the case at polar latitudes, which are instead characterized by extended periods of constant light (polar day) and constant darkness (polar night) with short periods of rapidly changing photoperiod in-between. During the polar day and polar night, animals inhabiting these latitudes are either free running, arrhythmic, or entrained to non-photic or photic cues other than photoperiod (Swade and Pittendrigh, 1967; van Oort et al., 2007; Stelzer and Chittka, 2010; Williams et al., 2011; Ashley et al., 2012; Steiger et al., 2013; Arnold et al., 2018; Hüppe et al., 2020; van Beest et al., 2020; Ware et al., 2020). On the Svalbard archipelago, which is among the northernmost landmasses in the Arctic $\left(74^{\circ}-81^{\circ} \mathrm{N}\right.$, Figure 1B), the Sun remains $\geq 6^{\circ}$ below the horizon between mid-November and February but is constantly above the horizon between mid-April and mid-September. Despite the high latitude, the climate is relatively mild due to warm ocean currents (average temperature in Longyearbyen in December: $-6.0^{\circ} \mathrm{C}$; Norwegian-Meterological-Institute, 2020). This is probably why some cold-hardy species can survive there year-round, including the world's most northerly distributed land bird, the Svalbard ptarmigan (Lagopus muta hyperborea; Figure 1A). Svalbard ptarmigan exhibit rhythmic activity during the short periods of light-dark cycles, but become arrhythmic during the polar day and polar night (Stokkan et al., 1986; Reierth and Stokkan, 1998). Similarly, plasma melatonin rhythms attenuate under such conditions (Reierth et al., 1999). This suggests that either the central circadian clock cannot sustain rhythmicity, or that

A

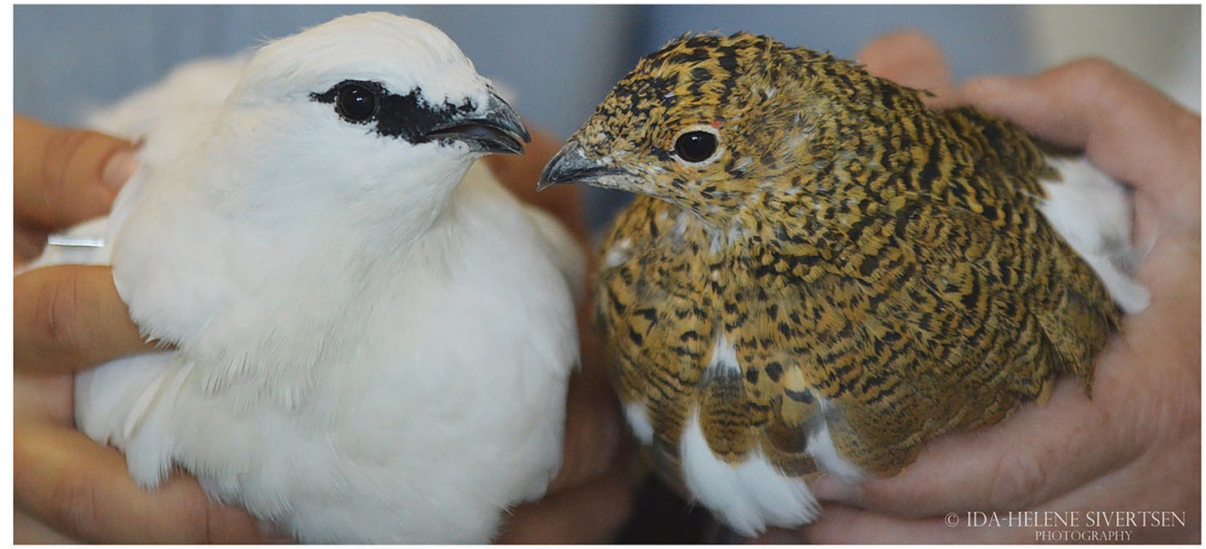

B

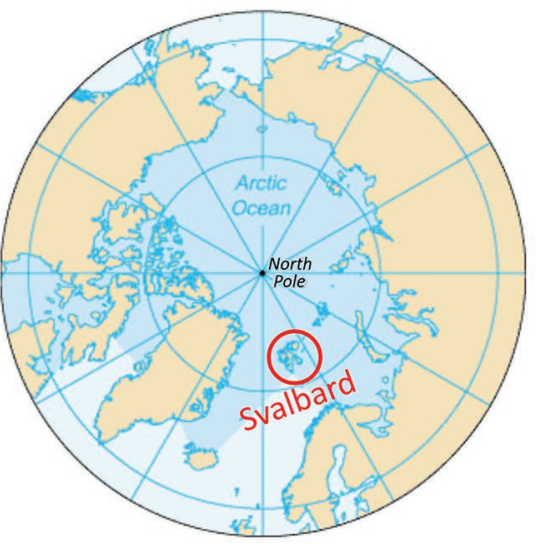

C

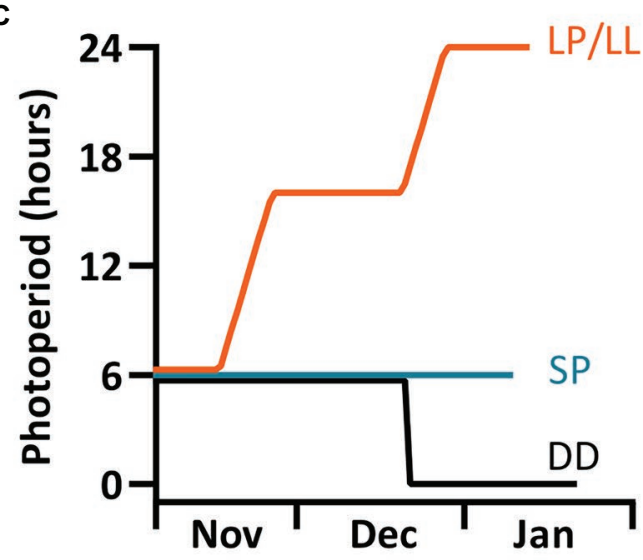

FIGURE 1 | Svalbard ptarmigan (Lagopus muta hyperborea) and experimental design. (A) The picture shows a Svalbard ptarmigan male in white winter plumage and a female in the cryptic brown summer plumage (C Ida-Helene Sivertsen). (B) The Svalbard ptarmigan is a subspecies of the rock ptarmigan (Lagopus muta) but is geographically isolated to the high Arctic archipelago of Svalbard and Franz Josef Land. (C) The experimental birds were bred at the University of Tromsø and were separated into three groups: the short photoperiod (SP) group remained under L:D 6:18. The LP/LL-group was gradually transferred from L:D 6:18 to L:D 16:8 (LP), and subsequently into constant light (LL). The constant darkness (DD) group was directly transferred from L:D 6:18 into DD. 
its molecular output is uncoupled from the peripheral tissue responses in constant light and constant darkness (Bloch et al., 2013). The above mentioned studies indicate that adaptation to life in the high Arctic has had profound effects on the circadian system. However, little is known of the physiological parameters that underlie circadian control. For this reason, we explored the implication of Arctic life on the circadian control of core body temperature $\left(T_{\mathrm{b}}\right)$.

Most endothermic animals display a daily $T_{\mathrm{b}}$ rhythm, which is under circadian control and characterized by lower $T_{\mathrm{b}}$ during the rest phase and higher $T_{\mathrm{b}}$ during the active phase (Menaker, 1959; Aschoff, 1983; Refinetti and Menaker, 1992). The function of the $T_{\mathrm{b}}$ rhythm is still disputed. The decrease in $T_{\mathrm{b}}$ during the rest phase might reduce energy costs by lowering the need for thermogenesis, though in the case of non-torpid and non-hibernating endotherms this reduction in $T_{\mathrm{b}}$ might be too small to have a significant impact on the energy budget (Menaker, 1959; Refinetti and Menaker, 1992). Temperature changes within the physiological range have also been shown to sustain rhythmicity in mammalian liver and lung cultures (Brown et al., 2002; Buhr et al., 2010) and it has been proposed that $T_{\mathrm{b}}$ serves the master clock to synchronize peripheral tissue. In a polar animal, $T_{\mathrm{b}}$ might serve the same purpose, especially since melatonin rhythms are often attenuated under the polar day and polar night (Miché et al., 1991; Reierth et al., 1999; Stokkan et al., 2007). There is evidence of sustained $T_{\mathrm{b}}$-rhythmicity through the polar day in Arctic ground squirrels (Urocitellus parryii; Long et al., 2005; Williams et al., 2011), but we are unaware of similar studies in Arctic birds.

In order to characterize the $T_{\mathrm{b}}$ rhythm in a truly Arctic bird and explore its possible circadian control, we implanted abdominal temperature loggers into captive Svalbard ptarmigan and recorded $T_{\mathrm{b}}$ and activity under short photoperiod (SP), long photoperiod (LP), in constant light (LL) and constant darkness (DD; Figure 1C). These photoperiodic treatments were chosen to study expression of the $T_{\mathrm{b}}$ and activity rhythm under entrained conditions (SP and LP) as well as under conditions without entrainable cues, i.e., in free running conditions (LL and DD). We also studied if there were differences in the timing of the rise in activity and $T_{\mathrm{b}}$ before the light-on signal when birds were under SP and LP, because this "anticipatory behavior" could indicate the presence of a functional time-keeping system.

\section{MATERIALS AND METHODS}

\section{Housing}

All animals were kept at the University of Tromsø in accordance with the EU directive 201/63/EU and licenses provided by the Nowegian Food Safety authority (Mattilsynet, permit nos. FOTS 8115 for 2015/2016 and FOTS 7971 for 2017/2018). Chicks were hatched from eggs laid by captive females in 2015 and 2017, and were reared either in outdoor cages under natural Troms $\varnothing$ photoperiod $\left(69^{\circ} 39^{\prime} \mathrm{N}, 18^{\circ} 57^{\prime} \mathrm{E}\right)$, or indoors with a photoperiod corresponding to the natural light cycle in Tromsø. When the chicks had reached a body mass of $500 \mathrm{~g}$ or more (usually by the end of September in the year of hatching), they were transferred to indoor cages with ad libitum access to food (Norgesfor, ref. no. OK2400 070316) and water. Ambient temperature was kept between 3 and $7^{\circ} \mathrm{C}$ throughout the experiment, which is within the thermo-neutral zone of physically mature Svalbard ptarmigan (Mortensen and Blix, 1986).

Illumination was provided by fluorescent strip lights (Osram L 58W 830 Lumilux, Osram, Munich, Germany), delivering 1,000 lux at floor level. Under constant darkness, illumination was provided by dim red light only (Northlight 36-6557, $15 \mathrm{~lm}$, Clas Ohlson, Insjön, Sweden), which delivered less than 1 lux at floor level.

\section{Photoperiodic Treatment}

All experiments were conducted from 30.09.2015 to 04.02.2016 and from 22.12.2017 to 08.04.2018. Birds hatched in the 2015/2016 season were exposed to three different photoperiodic treatments (Figure 1C). Initially, all birds were transferred into a photoperiod of L:D 12:12, which was gradually ( $1 \mathrm{~h} /$ day) decreased to L:D 6:18. The birds were subsequently kept in either L:D 6:18 (SP-group, $n=7$ ) or were gradually ( $1 \mathrm{~h} /$ day) transferred into L:D 16:8 (LP), and then to LL (LP/LL-group, $n=8)$. Birds from the 2017 cohort were directly transferred from L:D 6:18 to DD (DD-group, $n=3$ ). All birds were kept in their respective final light treatments until the end of the experiment. Photoperiodic treatments and exposure times for each bird can be found online at DataverseNO. ${ }^{1}$

\section{Core Body Temperature Recording}

Core body temperature was measured using iButton temperature loggers (DS1922L, Maxim Integrated, San Jose, CA, United States; accuracy: $\pm 0.5^{\circ} \mathrm{C}$, resolution: $\pm 0.0625^{\circ} \mathrm{C}$ ). All iButtons were calibrated in a high precision water bath (model 6025, Hart Scientific, Pleasant Grove, UT, United States), the temperature of which was monitored by a factory-calibrated (Nordtec, Gothenburg, Sweden) Testo 925 thermometer with a type K thermocouple (Testo, PA, United States; birds from the 2015 cohort) or a high precision glass thermometer (birds from the 2017 cohort). Calibration was performed in $5^{\circ} \mathrm{C}$ increments between 35 and $45^{\circ} \mathrm{C}$. This range covered the full range of core $T_{\mathrm{b}}$ shown by Svalbard ptarmigan over the course of the year (Nord and Folkow, 2018).

The calibrated iButtons were implanted into the abdominal cavity under gas anesthesia. Specifically, the birds were anesthetized with a $4 \%$ isoflurane air mix (Ref. No.: 9623, KDG Baxter, Deerfield, IL, United States) injected through an anesthetic facemask connected to an Ohmeda vaporizer (Ref. No.: 058294, BOC Health Care, Guildford, United Kingdom) and an isoflurane vaporizer (Vapor 2000, Ref. No.: ARXH1225, Dräger, Lübeck, Germany). Surgery started as soon as the bird showed muscle relaxation and did not respond to a physical stimulus (pinching of the skin).

The place of incision, i.e., ventrocaudal from the sternum, was located, plucked of feathers and disinfected with $2 \%$ iodine

${ }^{1}$ https://doi.org/10.18710/XLDXQ3 


\section{Core body temperature}

A
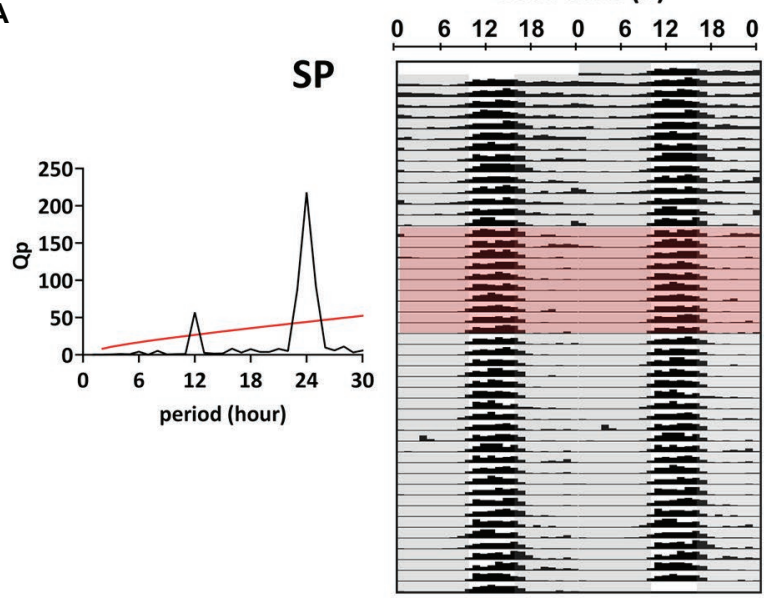

B

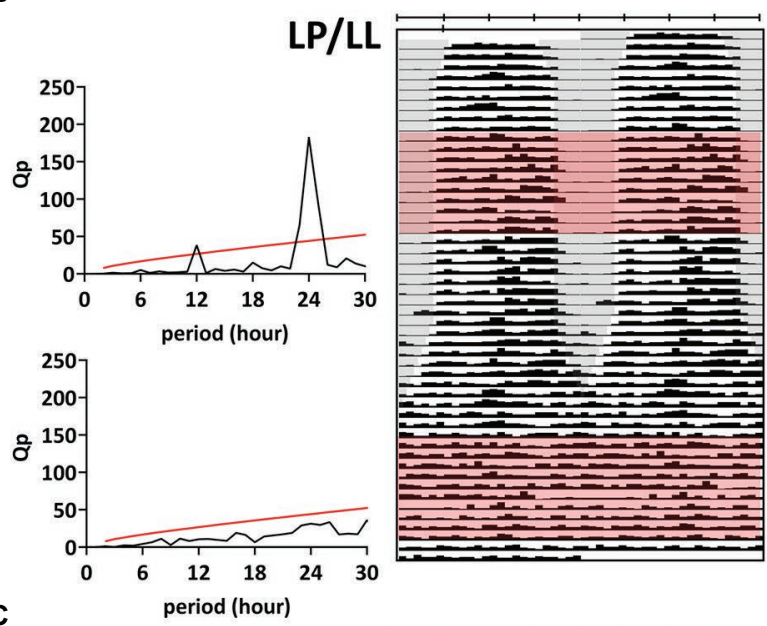

C
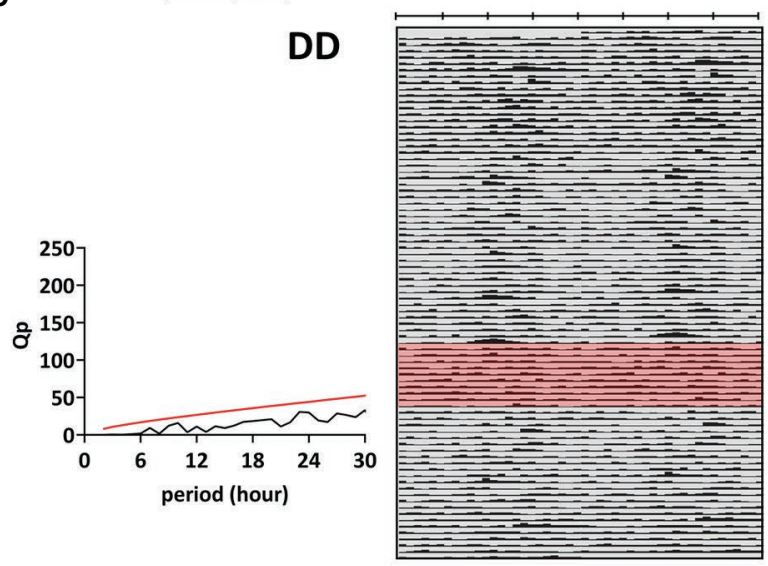

Clock time (h)

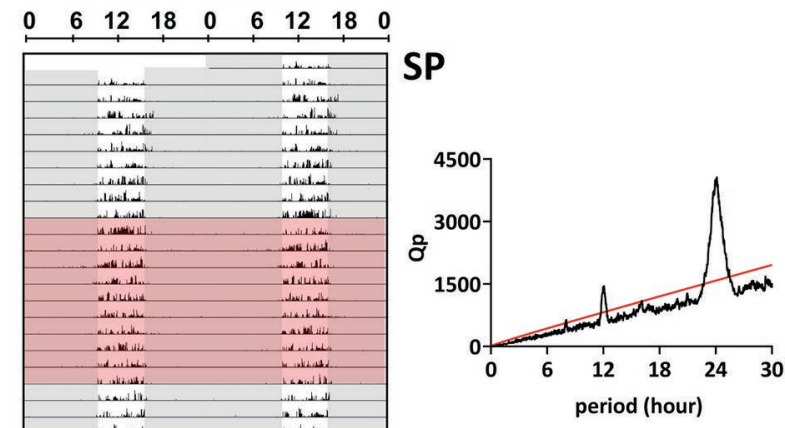

ind

in

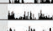

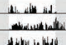

Whinition

E

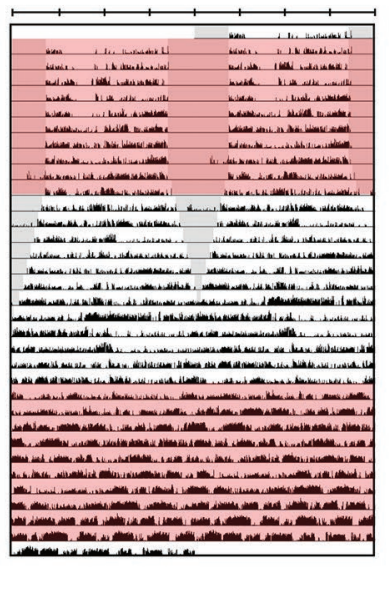

LP/LL
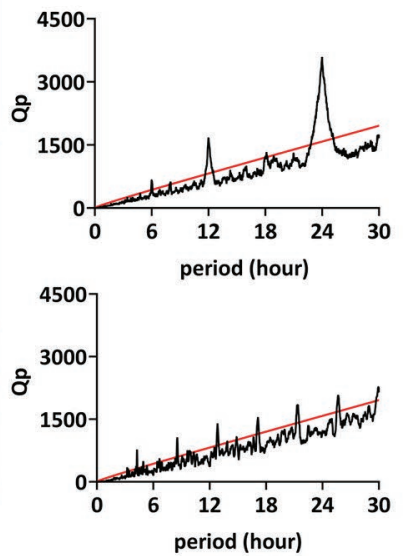

$\mathbf{F}$

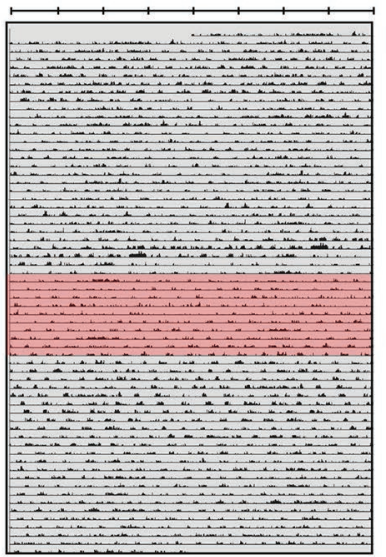

\section{DD}

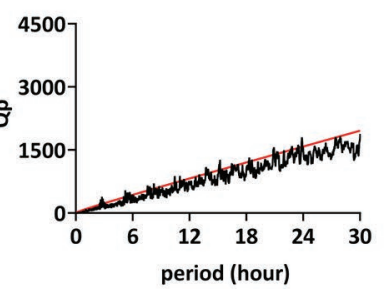

FIGURE 2 | Representative double-plotted actograms for body temperature $\left(T_{\mathrm{b}}\right)$ and activity. (A-C) $T_{\mathrm{b}}$ was plotted actogram-like between 40 and $42^{\circ} \mathrm{C}$ for representative birds from each group (bird IDs A: SP3, B: LP/LL11, C: DD3). (D-F) Actograms for normalized activity were plotted between 0 and 1 for representative birds from each group (bird IDs D: SP6, E: LP/LL15, F: DD2). $\chi^{2}$-periodograms were plotted for 10 consecutive days in each light treatment (red shading in actograms) and are displayed next to the respective recordings. Values above the red line indicate that the cycle period was significant $(p<0.05)$. Additional actograms and periodograms can be found in Supplementary Figures S1-S3. 


\section{Core body temperature}

A

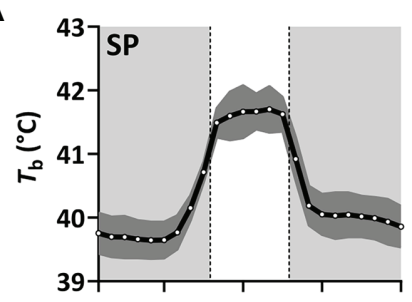

B

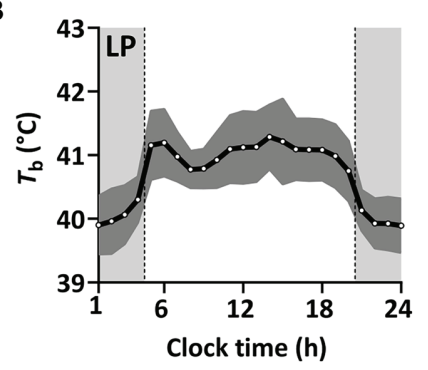

Activity

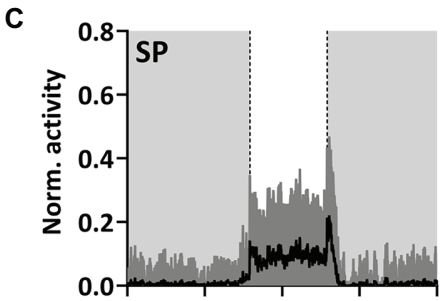

D

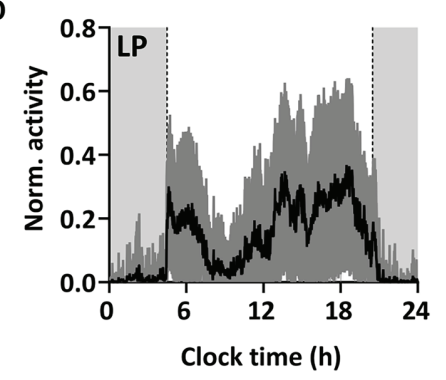

FIGURE 3 | Diel variation in $T_{\mathrm{b}}$ and activity in short and long photoperiod. (A,B) Mean $\pm \mathrm{SD} T_{\mathrm{b}}$ over the course of $24 \mathrm{~h}(01: 00$ to midnight) in SP (based on $222 \times 24$-h recordings from five birds) and LP (based on $184 \times 24$-h recordings from eight birds). $T_{\mathrm{b}}$ was measured every hour throughout the experiment. (C,D) Mean normalized activity \pm SD over the course of $24 \mathrm{~h}$ (midnight to midnight) in SP $(61 \times 24-\mathrm{h}$ recordings from three birds) and LP $(27 \times 24-\mathrm{h}$ recordings from three birds). Light gray shadowing in the panels indicate periods of darkness and dark gray indicates SD.

(ref. no.: 332452, Sanivo Pharma AS, Oslo, Norway). The skin and muscle tissue were cut along the linea alba and the sterilized $(70 \% \mathrm{EtOH})$ iButton was then inserted into the abdominal cavity. The muscle tissue was sutured with an absorbable 2-0 Polysorb string (Ref. No.: CL-811, Syneture, Dublin, Ireland) and was disinfected with $2 \%$ iodine. The skin was sutured with an absorbable 0 Dexon string (Ref. No.: 7232-61, Syneture, Dublin, Ireland) and again disinfected with $2 \%$ iodine. After surgery, the facemask was removed, and the bird was observed until it regained full consciousness. The birds were placed into their home cages as soon as they could stand unaided.

The iButtons recorded hourly $T_{\mathrm{b}}$ for the durations outlined online. ${ }^{2}$ Specifically, in the SP-group, the $T_{\mathrm{b}}$ of seven birds was recorded for 48 days (except for bird SP2 which was measured for 30 days). In the LP/LL-group, eight birds were recorded for 23 days under LP and 14 days under LL. In the DD-group, three birds were recorded for 83 days. All recordings were made at the full hour except for two birds in the SP-group, which recorded at half hour. At the end of the experiment, the implanted iButtons were recovered from euthanized birds and the data were downloaded using the Maxim Integrated software OneWireViewer (version 0.3.19.47).

\section{Activity Recording}

Locomotor activity was recorded continuously as movements per minute using passive infrared sensors (HSP 1131, Panasonic,

${ }^{2}$ https://doi.org/10.18710/XLDXQ3
Kadoma, Japan). These were installed on homebuilt circuit boards and mounted on the cage doors. Data were collected for a subset of three birds per photoperiodic group (determined by the number of available recording devices), using an Actimetrics CL200 USB interface coupled to ClockLab data acquisition software Version 2.61 (Actimetrics, Wilmette, IL, United States).

We recorded activity for the experiment during 9 days in three birds in the LP/LL-group under LP, 14 days in three birds in the LP/LL-group under LL, and 66 days in three birds in the DD-group. In the SP-group we measured activity for 12,18 , and 31 days in three birds. Activity was recorded as counts per minute and normalized from 0 to 1 for each individual bird prior to analysis and plotting.

\section{Data Handling and Analysis}

All graphs were plotted with GraphPad Prism 8 (Version 8.3.0, San Diego, CA, United States), except for the actograms, which were plotted using the ImageJ plugin ActogramJ (Schmid et al., 2011).

We plotted actograms for $T_{\mathrm{b}}$ and normalized activity for each bird over the whole experimental period. Actograms illustrate rhythmicity or the lack of it. All actograms were double-plotted to ease inspection. In a double-plotted actogram, one horizontal line represents 2 consecutive days (x-axis). Consecutive days are also plotted from top to bottom (y-axis). Normalized activity is displayed as bars of increasing heights between 0 and 1 on each line. This means that the higher the activity, the higher the bar. Low bars or the absence of 
bars indicate low activity and rest. Patterns or lack of rhythmicity can be observed by reading the actogram from top to button and by observing how phases of high and low activity relate to each other. We also adapted actograms to display $T_{\mathrm{b}}$ between 40 and $42^{\circ} \mathrm{C}$ to show $T_{\mathrm{b}}$ rhythmicity. Hence, $T_{\mathrm{b}}<40^{\circ} \mathrm{C}$ is blank in the actogram, while temperatures $>40^{\circ} \mathrm{C}$ were plotted as bars of increasing height up to $42^{\circ} \mathrm{C}$. Rhythmicity in these actograms was tested by calculating $\chi^{2}$-periodograms (Sokolove and Bushell, 1978) for 10 consecutive days for each bird in each light treatment. The 10-day period was chosen to coincide with reduced frequency of husbandry practices (see section "Bird Husbandry and the Effect on $T_{\mathrm{b}}$ ). The $\chi^{2}$-periodogram algorithm calculated $\mathrm{Q}_{\mathrm{p}}$ indices for each period between 1 and $30 \mathrm{~h} . \mathrm{Q}_{\mathrm{p}}$ follows a $\chi^{2}$ distribution, and values corresponding to a value $p<0.05$ were considered statistically significant.

We also plotted $T_{\mathrm{b}}$ and activity as mean \pm SD 24-h profiles for the SP and LP/LL group under LP. For each group, we calculated $T_{\mathrm{b}}$ peak and nadir for each respective light treatment. The peak and nadir means are based on maximum and minimum $T_{\mathrm{b}}$ of each day and each individual bird. We then compared the difference in daily $T_{\mathrm{b}}$ peak and nadir (henceforth "amplitude") between photoperiod groups. For this, we used a mixed effects model fitted with restricted likelihood (lmer function in the lme4 package; Bates et al., 2014) using $\mathrm{R}$ version 4.0.0 (R Core Team, 2020) implemented in RStudio (version 1.3.959). Photoperiodic treatment was used as the explanatory variable, and a random intercept for bird ID was included to account for repeated measurements. Group estimates for the amplitude and comparisons between the groups were obtained using the emmeans $\mathrm{R}$ package (Lenth et al., 2018). Periods of transition between different photoperiods, and two birds from the SP-group which recorded at half hour, were excluded from this analysis.

Core body temperature and activity were also plotted together for a 5-day period and for three birds for each photoperiod. In the periods selected for this purpose, the birds were acclimatized to their respective photoperiod for at least a week and were undisturbed apart from normal husbandry. In order to analyze effects of photoperiod on dawn anticipation, we calculated mean $T_{\mathrm{b}}$ and activity from the 5-day periods for $5 \mathrm{~h}$ before light-on when $T_{\mathrm{b}}$ was at its minimum and for $1 \mathrm{~h}$ after light-on. The activity mean was calculated as the mean of the $10 \mathrm{~min}$ immediately before each $T_{\mathrm{b}}$ measurement. We defined dawn anticipation as nocturnal rise in $T_{\mathrm{b}}$ or activity that preceded the light-on signal. The 6 -h period was analyzed by fitting a segmented linear regression (GraphPad 8) and we considered the break point of the segmented function (i.e., where the two regression segments meet) as the start of anticipatory rise in activity or $T_{\mathrm{b}}$. We plotted the data in Zeitgeber time $(\mathrm{ZT})$, in which ZT 0 corresponds to the light-on signal.

\section{Bird Husbandry and the Effect on $T_{\mathrm{b}}$}

Birds were monitored daily as part of routine husbandry. This might cause stress, which is known to cause increased
A

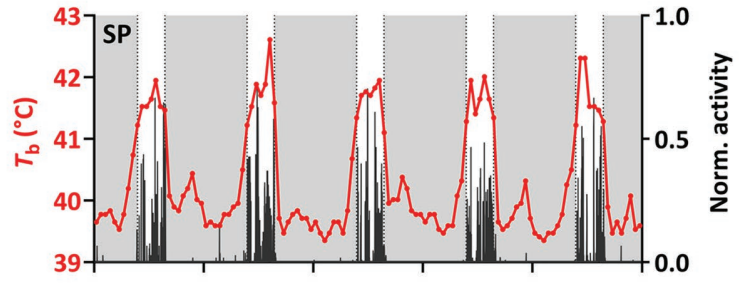

B

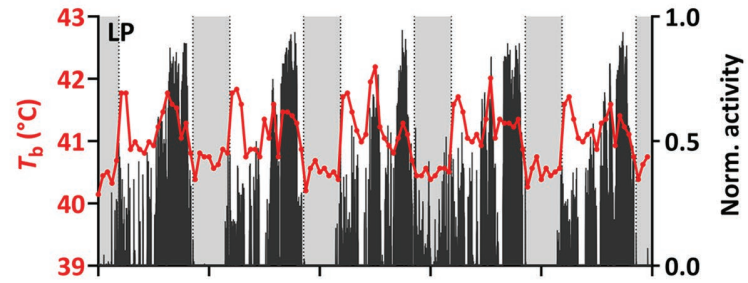

C
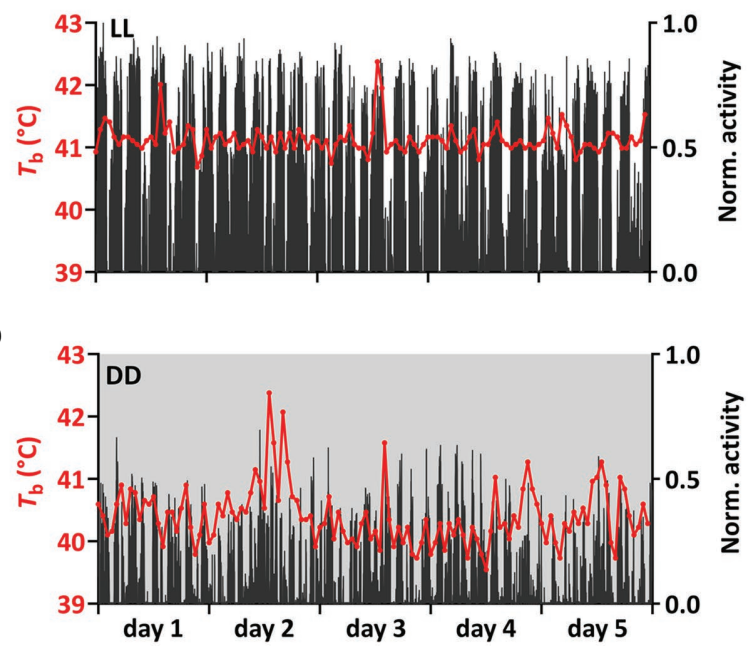

FIGURE 4 | Representative time series for $T_{\mathrm{b}}$ and activity. (A-D) $T_{\mathrm{b}}$ (red) was plotted together with normalized activity (black) for 5 consecutive days for one representative bird per experimental treatment (bird IDs $\mathbf{A}$ : SP6, B,C: LP/LL13, D: DD2). Light gray shadings indicate periods of darkness. Additional time series can be found in Supplementary Figure S4.

$T_{\mathrm{b}}$ in birds (Cabanac and Guillemette, 2001; Nord and Folkow, 2019). This might affect rhythmicity analyses, especially in LL and DD. For this reason, we kept records of the timing of husbandry and tested how these visits affected $T_{\mathrm{b}}$. We defined three categories (husbandry, $1 \mathrm{~h}$ after husbandry, and no husbandry) and assigned the respective $T_{\mathrm{b}}$ reading to each category for birds under LL and DD. The $T_{\mathrm{b}}$ means for each bird and each category were compared using paired $t$-test (Graphpad 8). In addition, we plotted husbandry in LL and DD in form of actograms and conducted $\chi^{2}$-periodogram analyses on the rhythm of husbandry and on $T_{\mathrm{b}}$ recording of all birds under LL and DD. 
A

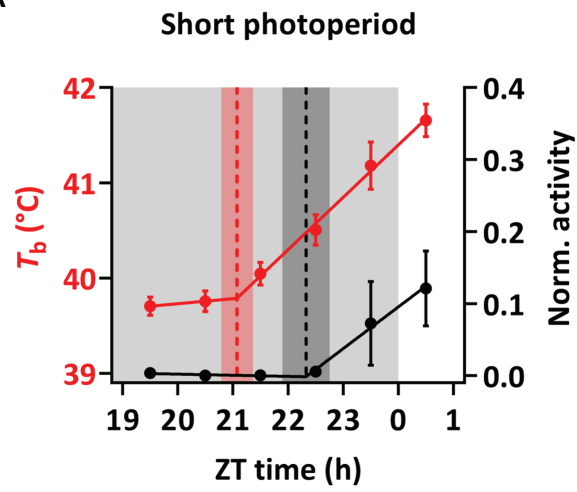

B

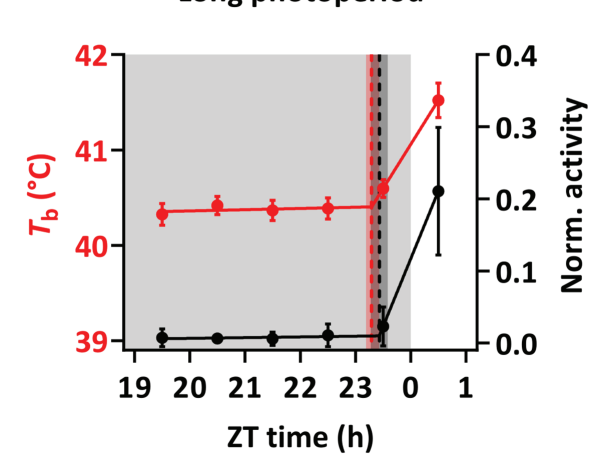

FIGURE 5 | Anticipatory rise in $T_{\mathrm{b}}$ based on segmental regression breakpoints. Hourly means of $T_{\mathrm{b}}$ (red) and activity (black) $5 \mathrm{~h}$ before and $1 \mathrm{~h}$ after the light-on signal, given in Zeitgeber time (ZT). (A) $T_{\mathrm{b}}$ in birds under SP was rising $2 \mathrm{~h} 56 \mathrm{~min}$ before the light-on signal while activity rises $1 \mathrm{~h} 40 \mathrm{~min}$ before light-on. (B) In birds under LP $T_{\mathrm{b}}$ increased $43 \mathrm{~min}$ before light-on, while activity rose $34 \mathrm{~min}$ before the light-on signal. The data correspond to the measurement in Figure 4 and Supplementary Figure S4 and are displayed as mean $\pm 95 \% \mathrm{Cl}$. Dotted lines indicate segmented regression breaking points and the shading shows the corresponding SD. Light gray shadings indicate periods of darkness.

\section{RESULTS}

Svalbard ptarmigan held under SP and LP displayed clear daily rhythms in $T_{\mathrm{b}}$ with a 24 -h period $\left(p<0.05\right.$ by $\chi^{2}$ periodogram), while birds under LL and DD showed no significant rhythmicity in $T_{\mathrm{b}}$ for a chosen 10-day period ( $p>0.05$ for all periods by $\chi^{2}$-periodogram; Figures $2 \mathrm{~A}-\mathrm{C}$ ). Husbandry caused stress related increase in $T_{\mathrm{b}}$ (Supplementary Figures S5, S6) and the 10-day periods (especially under DD) were chosen to coincide with less and randomized husbandry (Supplementary Figure S6).

The $T_{\mathrm{b}}$-rhythm under SP and LP is defined by decreased $T_{\mathrm{b}}$ during the dark-phase and increased $T_{\mathrm{b}}$ during the lightphase, which is expressed either as a single peak in SP (Figures 3A, 4A) or as a morning and one or several "afternoon peaks" in LP (Figures 3B, 4B). Birds under SP and LP displayed $T_{\mathrm{b}}$ amplitudes of $2.52 \pm 0.15^{\circ} \mathrm{C}$ and $2.27 \pm 0.12^{\circ} \mathrm{C}$, respectively (estimate \pm SE by mixed model analysis), while birds under LL and DD showed smaller differences between peak and nadir $(p<0.001$ by mixed model analysis) with $1.46 \pm 0.12^{\circ} \mathrm{C}$ and $1.30 \pm 0.19^{\circ} \mathrm{C}$, respectively. The amplitudes between SP vs. LP $(p=0.532)$ and LL vs. DD $(p=0.891)$ did not differ significantly. Results from the mixed model analyzing the amplitude are presented in Table 1.

Svalbard ptarmigan under SP and LP displayed clear 24-h rhythmicity in activity $\left(p<0.05\right.$ by $\chi^{2}$-periodogram; Figures 2D,E) with high activity in the light-phase and low activity in the dark-phase (Figures 3C,D). Similar to $T_{\mathrm{b}}$, birds under LP also displayed two distinct activity peaks during the light phase (Figure 3D). Birds under LL and DD showed various significant periods in activity between 1 and $30 \mathrm{~h}\left(p<0.05\right.$ by $\chi^{2}$-periodogram; Figures 2E,F).

Birds under SP showed a significant nocturnal increase in $T_{\mathrm{b}}$ preceding the light-on signal and the rise in activity
TABLE 1 | Differences in body temperature amplitude (i.e., the difference between the daily core $T_{\mathrm{b}}$ peak and $T_{\mathrm{b}}$ nadir; ${ }^{\circ} \mathrm{C}$ ) under different photoperiods.

\begin{tabular}{llcc}
\hline & Estimate (SE) & LR & $\boldsymbol{p}$ \\
\hline Model & $1.30(0.17)$ & & \\
Intercept & & 61.584 & $<0.001$ \\
Treatment & $1.30(0.19)$ & & \\
$\quad$ Constant darkness (DD) & $1.46(0.12)$ & & \\
$\quad$ Constant light (LL) & $2.27(0.12)$ & \\
$\quad$ Long photoperiod (LP, L:D 16:8) & $2.52(0.15)$ & \\
$\quad$ Short photoperiod (SP, L:D 6:18) & & \\
Contrast & $-0.16(0.22)$ & & \\
DD vs. LL & $-0.96(0.22)$ & & $<0.001$ \\
DD vs. LP & $-1.22(0.24)$ & $<0.001$ \\
DD vs. SP & $-0.81(0.17)$ & $<0.001$ \\
LL vs. LP & $-1.06(0.19)$ & $<0.001$ \\
LL vs. SP & $-0.26(0.19)$ & \\
LP vs. SP & & \\
\hline
\end{tabular}

Estimates $( \pm \mathrm{SE})$, likelihood ratios (LR) and $p$-values for the differences between photoperiodic treatments. Data were tested using a linear mixed effects model with bird ID as a random intercept. $p$-values and group estimates were obtained and compared using the emmeans package in $\mathrm{R}$.

(Figures 4, 5). Under SP, both activity and $T_{\mathrm{b}}$ increased in the 5 -h period immediately preceding the light-on signal. However, $T_{\mathrm{b}}$ rose $3 \mathrm{~h}$ before light-on [segmented regression breakpoint: ZT 21:04 \pm 00:17 (hh:mm \pm SD)] whereas activity increased $1 \mathrm{~h} 40 \mathrm{~m}$ before (breakpoint: ZT 22:20 \pm 00:26). In LP, birds showed increased $T_{\mathrm{b}}$ and activity starting around half an hour before light-on (breakpoint for $T_{\mathrm{b}}$ : ZT 23:17 $\pm 00: 06$; and for activity: ZT 23:26 \pm 00:09).

We also observed that SP-birds often expressed a small increase in $T_{\mathrm{b}}$ in the dark-phase around $11 \mathrm{~h}$ after the last light-on switch (ZT 11:05 \pm 1:00, mean \pm SD based on analysis in Figure 4 and Supplementary Figure S4). The nocturnal peak was similar to the expression of the "afternoon peak" in LP-birds that occurred $9 \mathrm{~h}$ after the light-on signal (ZT 8:51 \pm 1:11). 


\section{DISCUSSION}

In this study, we measured $T_{\mathrm{b}}$ and activity in Svalbard ptarmigan under photoperiods that were representative of those experienced during their annual cycle in the wild. All recorded $T_{\mathrm{b}}$ fell within the reported range of birds (Prinzinger et al., 1991) and were comparable to previous measurements of $T_{\mathrm{b}}$ during subjective daytime in Svalbard ptarmigan (Nord and Folkow, 2018). In SP and LP, birds showed pronounced rhythms in $T_{\mathrm{b}}$ with high temperatures during the light-phase and low temperature during the dark-phase. In LL and DD, the difference between maximal and minimal $T_{\mathrm{b}}$ within a 24 -h period was attenuated and our periodogram analysis suggests weakened circadian control over $T_{\mathrm{b}}$ rhythms under these constant photic conditions. Occasionally, birds in LL and DD continued to show transient peaks in $T_{\mathrm{b}}$, which are reminiscent of sustained rhythmicity. However, these peaks coincided with visits for husbandry and we ascribe the observation to consequences of a stress-related increase in $T_{\mathrm{b}}$ (Cabanac and Guillemette, 2001; Nord and Folkow, 2019).

Activity was also rhythmic with a 24 -h period in SP and LP, which was not sustained in LL and DD. This is in accordance with previous studies on activity rhythms in Svalbard ptarmigan (Stokkan et al., 1986; Reierth and Stokkan, 1998). Instead of a clear 24-h rhythm, birds under LL and DD showed various significant periods between 1 and $30 \mathrm{~h}$. Especially birds under LL appeared to express ultradian activity rhythms with a period of ca. $4 \mathrm{~h}$ (Figure 2E) of which subsequent peaks in the periodogram could be subharmonics to the fundamental ultradian period. In the absence of an environmental light-dark cycle, the ultradian rhythm might reflect foraging activity and subsequent rest in Svalbard ptarmigan. At this stage, we can only speculate if this activity pattern is under endogenous control of an ultradian oscillator (Bourguignon and Storch, 2017) or if it is produced by the interplay of hunger and satiety.

Core body temperature rose in anticipation to the light-on signal and, in birds under SP, prior to rises in activity. This suggests, firstly, that, as in most other endothermic animals, $T_{\mathrm{b}}$ is a distinct endogenous feature and not only a consequence of activity (Menaker, 1959; Aschoff, 1983; Refinetti and Menaker, 1992). Secondly, it suggests that the $T_{\mathrm{b}}$-cycle in Svalbard ptarmigan is controlled by a time-measuring system, which accurately anticipates the light-on signal. In nature, this anticipatory rise in $T_{\mathrm{b}}$ might ensure optimal bodily function at the start of the active phase. In mammals, cycles in $T_{\mathrm{b}}$ might be utilized by the central circadian system to impose its rhythm on peripheral tissues (Brown et al., 2002; Buhr et al., 2010). It is possible that Svalbard ptarmigan (and other birds) use $T_{\mathrm{b}}$ in the same manner to ensure synchronized physiology in the short periods of light-dark cycles in-between the long stretches of polar day and polar night. Due to the absence of measurable circadian rhythms in $T_{\mathrm{b}}$ and activity in $\mathrm{LL}$ and $\mathrm{DD}$, we propose that the central circadian system of Svalbard ptarmigan either uncouples from its output, or dampens in rhythmicity, when there is no periodic environmental synchronization (Bloch et al., 2013). This might ensure aroundthe-clock foraging without endogenous restraints during the polar day and polar night. However, we cannot exclude the possibility that under natural conditions Svalbard ptarmigan still express rhythms in $T_{\mathrm{b}}$ during the polar day and polar night due to entrainment to other photic or non-photic cues (Long et al., 2005; Ashley et al., 2012).

We also observed transient increases in $T_{\mathrm{b}}$ in the dark-phase of birds under SP. This could reflect nocturnal digestive activity (Rashotte et al., 1997). Alternatively, this observation might be further support for a circadian drive in $T_{\mathrm{b}}$ under light-dark cycles, in which case the transient nocturnal $T_{\mathrm{b}}$-peak in SP would correspond to the "afternoon peak" seen in LP birds.

Our findings suggest that Svalbard ptarmigan are using a circadian system under SP and LP to control their $T_{b}$. Under prolonged LL and DD, this circadian control of $T_{\mathrm{b}}$ and activity seems to weaken. They can, therefore, utilize the benefits of a circadian system during times of a rhythmic environment but are able to escape its restrictions in constant photic conditions. Instead of a circadian rhythm, Svalbard ptarmigan show signs of ultradian rhythmicity in activity, especially under LL, but we cannot resolve if this rhythm is endogenous or produced by the interaction of hunger and satiety. Future research should aim to elucidate how Svalbard ptarmigan achieve their duality of circadian organization and how ultradian rhythmicity is controlled.

\section{DATA AVAILABILITY STATEMENT}

The datasets presented in this study can be found in online repositories. The names of the repository/repositories and accession number(s) can be found in the article/Supplementary Material.

\section{ETHICS STATEMENT}

The animal study was reviewed and approved by the Norwegian Food Safety Authority (Mattilsynet).

\section{AUTHOR CONTRIBUTIONS}

DA, DH, and GW: conceptualization and project administration. DA: data curation and writing - original draft. DA, AN, and GW: formal analysis, investigation, and visualization. $\mathrm{DH}$ and GW: funding acquisition and supervision. DA, AN, DH, and GW: methodology and writing - review and editing. $\mathrm{AN}, \mathrm{DH}$, and $\mathrm{GW}$ : resources. $\mathrm{AN}$ : software. $\mathrm{AN}$ and $\mathrm{GW}$ : validation. All authors contributed to the article and approved the submitted version.

\section{FUNDING}

$\mathrm{DA}, \mathrm{DH}$, and GW were supported by grants from the Troms $\varnothing$ Research Foundation (TFS2016DH) and the Human Frontiers Science Program (RGP0030/2015) to DH. DA and GW received further funding through the Master Program of the University of 
Tromsø - The Arctic University. AN was supported by the Swedish Research Council (grant no. 637-2013-7442), the Carl Trygger Foundation for Scientific Research (grant no. CTS14: 347) and the Birgit and Hellmuth Hertz Foundation/the Royal Physiographic Society of Lund (grant no. 2017-39034).

\section{ACKNOWLEDGMENTS}

We would like to thank the animal technicians from the Arctic Chronobiology and Physiology research group. Their dedication

\section{REFERENCES}

Arnold, W., Ruf, T., Loe, L. E., Irvine, R. J., Ropstad, E., Veiberg, V., et al. (2018). Circadian rhythmicity persists through the polar night and midnight sun in svalbard reindeer. Sci. Rep. 8:14466. doi: 10.1038/s41598-018-32778-4

Aschoff, J. (1983). Circadian control of body temperature. J. Therm. Biol. 8, 143-147. doi: 10.1016/0306-4565(83)90094-3

Ashley, N. T., Schwabl, I., Goymann, W., and Buck, C. L. (2012). Keeping time under the midnight sun: behavioral and plasma melatonin profiles of free-living Lapland longspurs (Calcarius lapponicus) during the Arctic summer. J. Exp. Zool. A Ecol. Genet. Physiol. 319, 10-22. doi: 10.1002/jez.1768

Bates, D., Mächler, M., Bolker, B., and Walker, S. (2014). Fitting linear mixedeffects models using lme4. arXiv [Preprint]. doi: 10.18637/jss.v067.i01.

Bloch, G., Barnes, B. M., Gerkema, M. P., and Helm, B. (2013). Animal activity around the clock with no overt circadian rhythms: patterns, mechanisms and adaptive value. Proc. Biol. Sci. 280:20130019. doi: 10.1098/ rspb.2013.0019

Bourguignon, C., and Storch, K. -F. (2017). Control of rest: activity by a dopaminergic ultradian oscillator and the circadian clock. Front. Neurol. 8:614. doi: $10.3389 /$ fneur.2017.00614

Brown, S. A., Zumbrunn, G., Fleury-Olela, F., Preitner, N., and Schibler, U. (2002). Rhythms of mammalian body temperature can sustain peripheral circadian clocks. Curr. Biol. 12, 1574-1583. doi: 10.1016/S0960-9822(02) $01145-4$

Buhr, E. D., Yoo, S. -H., and Takahashi, J. S. (2010). Temperature as a universal resetting cue for mammalian circadian oscillators. Science 330, 379-385. doi: $10.1126 /$ science. 1195262

Cabanac, A., and Guillemette, M. (2001). Temperature and heart rate as stress indicators of handled common eider. Physiol. Behav. 74, 475-479. doi: 10.1016/ S0031-9384(01)00586-8

Daan, S., Spoelstra, K., Albrecht, U., Schmutz, I., Daan, M., Daan, B., et al. (2011). Lab mice in the field: unorthodox daily activity and effects of a dysfunctional circadian clock allele. J. Biol. Rhythms 26, 118-129. doi: $10.1177 / 0748730410397645$

Darlington, T. K., Wager-Smith, K., Ceriani, M. F., Staknis, D., Gekakis, N., Steeves, T. D., et al. (1998). Closing the circadian loop: CLOCK-induced transcription of its own inhibitors per and tim. Science 280, 1599-1603. doi: $10.1126 /$ science.280.5369.1599

DeCoursey, P. J., and Krulas, J. R. (1998). Behavior of SCN-lesioned chipmunks in natural habitat: a pilot study. J. Biol. Rhythms 13, 229-244. doi: $10.1177 / 074873098129000075$

DeCoursey, P. J., Krulas, J. R., Mele, G., and Holley, D. C. (1997). Circadian performance of suprachiasmatic nuclei (SCN)-lesioned antelope ground squirrels in a desert enclosure. Physiol. Behav. 62, 1099-1108. doi: 10.1016/ S0031-9384(97)00263-1

DeCoursey, P., Walker, J., and Smith, S. (2000). A circadian pacemaker in free-living chipmunks: essential for survival? J. Comp. Physiol. A. 186, 169-180. doi: 10.1007/s003590050017

Hardin, P. E., Hall, J. C., and Rosbash, M. (1990). Feedback of the Drosophila period gene product on circadian cycling of its messenger RNA levels. Nature 343, 536-540. doi: 10.1038/343536a0

Hüppe, L., Payton, L., Last, K., Wilcockson, D., Ershova, E., and Meyer, B. (2020). Evidence for oscillating circadian clock genes in the copepod Calanus and experience are indispensable for past, current, and future research. We would also like to thank Dr. Alexander West for his insightful comments, motivational words, and ongoing support.

\section{SUPPLEMENTARY MATERIAL}

The Supplementary Material for this article can be found online at: https://www.frontiersin.org/articles/10.3389/fphys.2021.633866/ full\#supplementary-material

finmarchicus during the summer solstice in the high Arctic. Biol. Lett. 16:20200257. doi: 10.1098/rsbl.2020.0257

Lenth, R., Singmann, H., and Love, J. (2018). Emmeans: Estimated marginal means, aka least-squares means. $\mathrm{R}$ package version, 1.

Long, R. A., Martin, T. J., and Barnes, B. M. (2005). Body temperature and activity patterns in free-living arctic ground squirrels. J. Mammal. 86, 314-322. doi: 10.1644/BRG-224.1

Menaker, M. (1959). Endogenous rhythms of body temperature in hibernating bats. Nature 184, 1251-1252. doi: 10.1038/1841251a0

Menaker, M., Moreira, L., and Tosini, G. (1997). Evolution of circadian organization in vertebrates. Braz. J. Med. Biol. Res. 30, 305-313. doi: 10.1590/S0100879X1997000300003

Miché, F., Vivien-Roels, B., Pévet, P., Spehner, C., Robin, J., and Le Maho, Y. (1991). Daily pattern of melatonin secretion in an Antarctic bird, the emperor penguin, Aptenodytes forsteri: seasonal variations, effect of constant illumination and of administration of isoproterenol or propranolol. Gen. Comp. Endocrinol. 84, 249-263. doi: 10.1016/0016-6480(91)90048-B

Mortensen, A., and Blix, A. (1986). Seasonal changes in resting metabolic rate and mass-specific conductance in Svalbard ptarmigan, Norwegian rock ptarmigan and Norwegian willow ptarmigan. Ornis Scand. 17, 8-13. doi: $10.2307 / 3676746$

Nord, A., and Folkow, L. P. (2018). Seasonal variation in the thermal responses to changing environmental temperature in the world's northernmost land bird. J. Exp. Biol. 221:jeb171124. doi: 10.1242/jeb.171124

Nord, A., and Folkow, L. P. (2019). Ambient temperature effects on stressinduced hyperthermia in Svalbard ptarmigan. Biol. Open 8:bio043497. doi: 10.1242/bio.043497

Norwegian-Meterological-Institute (2020). Free meteorological data. Available at: https://www.met.no/ (Accessed November 6, 2020).

Pevet, P., and Challet, E. (2011). Melatonin: both master clock output and internal time-giver in the circadian clocks network. J. Physiol. Paris 105, 170-182. doi: 10.1016/j.jphysparis.2011.07.001

Pittendrigh, C. S. (1960). Circadian rhythms and the circadian organization of living systems. Cold Spring Harb. Symp. Quant. Biol. 25, 159-184. doi: 10.1101/SQB.1960.025.01.015

Prinzinger, R., Pressmar, A., and Schleucher, E. (1991). Body temperature in birds. Comp. Biochem. Physiol. A Physiol. 99, 499-506. doi: 10.1016/03009629(91)90122-S

R Core Team (2020). R: A language and environment for statistical computing. R Foundation for Statistical Computing, Vienna, Austria. Available at: https:// www.R-project.org

Rashotte, M. E., Phillips, D. L., and Henderson, R. P. (1997). Nocturnal digestion, cloacal excretion, and digestion-related thermogenesis in pigeons (Columba livia). Physiol. Behav. 61, 83-92. doi: 10.1016/S0031-9384(96)00353-8

Refinetti, R., and Menaker, M. (1992). The circadian rhythm of body temperature. Physiol. Behav. 51, 613-637. doi: 10.1016/0031-9384(92)90188-8

Reierth, E., and Stokkan, K. -A. (1998). Activity rhythm in high arctic svalbard ptarmigan (Lagopus mutus hyperboreus). Can. J. Zool. 76, 2031-2039. doi: 10.1139/z98-173

Reierth, E., Van't Hof, T. J., and Stokkan, K. -A. (1999). Seasonal and daily variations in plasma melatonin in the high-arctic Svalbard ptarmigan (Lagopus mutus hyperboreus). J. Biol. Rhythms 14, 314-319. doi: 10.1177/0748730 99129000731 
Schmid, B., Helfrich-Förster, C., and Yoshii, T. (2011). A new ImageJ plug-in "ActogramJ" for chronobiological analyses. J. Biol. Rhythms 26, 464-467. doi: 10.1177/0748730411414264

Sokolove, P. G., and Bushell, W. N. (1978). The chi square periodogram: its utility for analysis of circadian rhythms. J. Theor. Biol. 72, 131-160. doi: 10.1016/0022-5193(78)90022-X

Spoelstra, K., Wikelski, M., Daan, S., Loudon, A. S., and Hau, M. (2016). Natural selection against a circadian clock gene mutation in mice. Proc. Natl. Acad. Sci. U. S. A. 113, 686-691. doi: 10.1073/pnas.1516442113

Steiger, S. S., Valcu, M., Spoelstra, K., Helm, B., Wikelski, M., and Kempenaers, B. (2013). When the sun never sets: diverse activity rhythms under continuous daylight in free-living arctic-breeding birds. Proc. Biol. Sci. 280:20131016. doi: $10.1098 / \mathrm{rspb} .2013 .1016$

Stelzer, R. J., and Chittka, L. (2010). Bumblebee foraging rhythms under the midnight sun measured with radiofrequency identification. BMC Biol. 8:93. doi: 10.1186/1741-7007-8-93

Stokkan, K. -A., Mortensen, A., and Blix, A. S. (1986). Food intake, feeding rhythm, and body mass regulation in Svalbard rock ptarmigan. Am. J. Physiol. 251, R264-R267. doi: 10.1152/ajpregu.1986.251.2.R264

Stokkan, K. A., Van Oort, B. E., Tyler, N. J., and Loudon, A. S. (2007). Adaptations for life in the Arctic: evidence that melatonin rhythms in reindeer are not driven by a circadian oscillator but remain acutely sensitive to environmental photoperiod. J. Pineal Res. 43, 289-293. doi: 10.1111/j.1600079X.2007.00476.x

Swade, R. H., and Pittendrigh, C. S. (1967). Circadian locomotor rhythms of rodents in the Arctic. Am. Nat. 101, 431-466. doi: 10.1086/282510 van Beest, F. M., Beumer, L. T., Chimienti, M., Desforges, J. -P., Huffeldt, N. P., Pedersen, S. H., et al. (2020). Environmental conditions alter behavioural organization and rhythmicity of a large Arctic ruminant across the annual cycle. R. Soc. Open Sci. 7:201614. doi: 10.1098/rsos.201614

van Oort, B. E., Tyler, N. J., Gerkema, M. P., Folkow, L., and Stokkan, K. -A. (2007). Where clocks are redundant: weak circadian mechanisms in reindeer living under polar photic conditions. Naturwissenschaften 94, 183-194. doi: 10.1007/s00114-006-0174-2

Ware, J. V., Rode, K. D., Robbins, C. T., Leise, T., Weil, C. R., and Jansen, H. T. (2020). The clock keeps ticking: circadian rhythms of free-ranging polar bears. J. Biol. Rhythms 35, 180-194. doi: 10.1177/0748730419900877

Williams, C. T., Barnes, B. M., and Buck, C. L. (2011). Daily body temperature rhythms persist under the midnight sun but are absent during hibernation in free-living arctic ground squirrels. Biol. Lett. 8, 31-34. doi: 10.1098/rsbl.2011.0435

Conflict of Interest: The authors declare that the research was conducted in the absence of any commercial or financial relationships that could be construed as a potential conflict of interest.

Copyright (c) 2021 Appenroth, Nord, Hazlerigg and Wagner. This is an open-access article distributed under the terms of the Creative Commons Attribution License (CC BY). The use, distribution or reproduction in other forums is permitted, provided the original author(s) and the copyright owner(s) are credited and that the original publication in this journal is cited, in accordance with accepted academic practice. No use, distribution or reproduction is permitted which does not comply with these terms. 